\title{
Sistemas produtivos de caprinocultura leiteira no semiárido paraibano: caracterização, principais limitantes e avaliação de estratégias de intervenção ${ }^{1}$
}

\author{
Beatriz Riet-Correa², Sara Vilar Dantas Simões ${ }^{2 *}$, José Morais Pereira Filho², \\ Sérgio Santos de Azevedo², Diego Barreto de $\mathrm{Melo}^{2}$, Jouberdan Aurino Batista ${ }^{2}$, \\ Eldinê G. de Miranda Neto ${ }^{2}$ e Franklin Riet-Correa ${ }^{2}$
}

\begin{abstract}
Riet-Correa B., Simões S.V.D., Pereira Filho J.M., Azevedo S.S.A., Melo D.B., Batista J.A., Miranda Neto E.G. \& Riet-Correa F. 2013. [Productive systems of dairy goats in the semiarid of Paraiba: characterization, major limiting factors and evaluation of intervention strategies.] Sistemas produtivos de caprinocultura leiteira no semiárido paraibano: caracterização, principais limitantes e avaliação de estratégias de intervenção. Pesquisa Veterinária Brasileira 33(3):345-352. Hospital Veterinário, Universidade Federal de Campina Grande, Av. Universitária s/n, Patos, PB 58700-970, Brazil. E-mail: saravilar@bol.com.br

Through a multidisciplinary study, eight dairy goat farms from the semiarid of Paraíba were studied for a period of two years with the aim to identify the main limiting factors for milk production and to propose and evaluate intervention strategies. A questionnaire was used to obtain information about the farms and their herd management. The forage availabilities were evaluated and proposals were made for correction. The animals were identified to facilitate the zootechnical bookkeeping and the milk production control. The major diseases were diagnosed. Analysis of variance, multiple linear regression and test were used for data analysis. The average animal numbers in the herds were 53 at the start of the first year, 62 in the end of the year, and 49 in the second year. None herd had a defined breed. In the first year, seven farms had forage deficiency during the dry season, but only two during the rainy season. In the second year, after technical advertisement, six farms still had forage deficiency during the dry season and only two during the rainy season; however in six farms the yearly forage production was adequate and storing fodder during the rainy season would prevent the deficit during drought. The average milk production per goat was 1.19 liters. The most inadequate goat facilities were those used to keep the goat kids. Zootechnical bookkeeping was originally not practiced in any farm at the start of the study, but it was gradually and partially established. The main diseases recorded were caseous lymphadenitis, subclinical mastitis, keratoconjunctivitis and contagious ecthyma. The prevalence of subclinical mastitis, caseous lymphadenitis and gastrointestinal parasitoses were reduced after technical assistance. Reproductive problems were reported in $75 \%$ of the farms. Four herds had goat kid mortality rates higher than those acceptable. After analyzing the data, it can be concluded that a continuous and multidisciplinary technical assistance may minimize the factors limiting dairy goat production. The study showed that farmers accept the new technologies if they are appropriate to the systems and are gradually implemented.
\end{abstract}

INDEX TERMS: Dairy goats, sanitary aspects, management, Paraíba, Brazil.

\footnotetext{
${ }^{1}$ Recebido em 5 de setembro de 2012.

Aceito para publicação em 8 de janeiro de 2013.

${ }^{2}$ Programa de Pós-Graduação em Medicina Veterinária, Universidade Federal de Campina Grande (UFCG), Hospital Veterinário, Avenida Universitária s/n, Patos, PB 58700-970, Brasil. *Autor para correspondência: saravilar@bol.com.br
}

RESUMO-- Oito propriedades de leite caprino do semiárido paraibano foram acompanhadas, multidisciplinarmente, durante dois anos, com os objetivos de identificar os principais fatores limitantes da produção, assim como propor e avaliar estratégias de intervenção. Utilizou-se um questionário para obtenção de informações sobre as propriedades 
e práticas de manejo. Avaliou-se o balanço forrageiro de cada propriedade e foram feitas propostas para correção. Os animais foram identificados para que se viabilizasse a escrituração zootécnica e o controle da produção individual de leite. 0 diagnóstico das principais enfermidades foi estabelecido. Para análise dos dados, utilizou-se análise de variância, regressão linear múltipla e o teste t. 0 número médio de animais nos rebanhos era 53 cabeças (início do estudo), 62 (final do primeiro ano) e 49 (último ano). Nenhum rebanho tinha padrão racial definido. $\mathrm{Na}$ análise do balanço anual de forragem do primeiro ano, sete propriedades tiveram déficit forrageiro na seca, enquanto apenas duas apresentaram déficit durante o período chuvoso. No segundo ano, após as intervenções, seis das oito propriedades apresentaram déficit durante a seca e duas durante a chuva. Entretanto, em seis propriedades, se fossem armazenadas forragens no período da chuva, a quantidade de alimento produzida durante a chuva seria suficiente para manter os animais durante a estação seca. A média da produção de leite diária nas propriedades foi 1,19 litros por cabra. Os problemas mais graves de instalações foram identificados nos cabriteiros. No início do estudo, nenhum produtor realizava escrituração zootécnica, a qual foi gradativa e parcialmente implantada. As principais enfermidades diagnosticadas foram parasitoses gastrintestinais, linfadenite caseosa, mastite subclínica, ectima contagioso e ceratoconjuntivite. A prevalência de linfadenite, mastite e parasitoses gastrintestinais foram reduzidas, após a adoção de práticas adequadas. Problemas reprodutivos foram relatados por $75 \%$ dos proprietários. Em quatro propriedades, as taxas de mortalidade de animais jovens foram maiores do que as aceitáveis (8\%). Após análise dos dados, observou-se que a assistência técnica permanente e multidisciplinar pode minimizar os fatores limitantes à caprinocultura leiteira. 0 estudo demonstrou que os produtores aceitam a implantação de novas tecnologias, desde que estas sejam gradativamente implantadas e adequadas aos sistemas de produção.

TERMOS DE INDEXAÇÃO: Caprinocultura leiteira, aspectos sanitários, manejo, Paraíba, Brasil.

\section{INTRODUÇÃO}

A pecuária, em função de sua maior capacidade de adaptação à seca, quando comparada às explorações agrícolas, representa uma das mais importantes atividades do agronegócio no semiárido brasileiro e tem se constituído num dos principais fatores para a garantia da segurança alimentar das famílias rurais e geração de emprego e renda (Lima 2009). Neste contexto, considerando que 92\% do rebanho caprino nacional se concentra na Região Nordeste, fica evidente a importância da caprinocultura para a economia da região. Na Paraíba, desde o ano 2000, a caprinocultura leiteira tem recebido incentivos através da compra da produção de leite pelo governo estadual e das ações do "Pacto Novo Cariri" que, entre outras atividades, promoveu um sistema de aquisição, industrialização e distribuição de leite, o "Programa do Leite", que também incluiu o Sertão Paraibano. Atualmente, no Cariri, Sertão e Curimataú, a ca- prinocultura tornou-se a principal atividade agropecuária e econômica. Nessas regiões, há um rebanho caprino de 624 mil cabeças, dos quais 25\% são cabras leiteiras. Nessas regiões, há um rebanho caprino de 624 mil cabeças, dos quais $25 \%$ são cabras leiteiras. Um total de 1.133 famílias agricultoras dependem da atividade e estão distribuídas em 37 associações, que possuem 11 pequenas usinas de beneficiamento (Suassuna 2012).

Apesar da assistência técnica permanente oferecida pelo Programa do Leite observa-se que, na casuística do Hospital Veterinário da UFCG, são frequentes os atendimentos a caprinos provenientes desses sistemas produtivos. Além disso, em trabalhos de pesquisa e extensão da UFCG, observam-se diversos problemas nas propriedades, que interferem na produtividade do rebanho. De acordo com Pinheiro et al. (2000), os sistemas de produção de caprinos e ovinos na região têm se caracterizado por baixos índices produtivos decorrentes, principalmente, de práticas inadequadas de manejo, más condições sanitárias, baixa capacidade de investimento e absorção tecnológica e irregularidades na disponibilidade anual de alimentos. Trabalhos prévios focalizaram o perfil sanitário da caprinocultura leiteira na Paraíba (Bandeira et al. 2007, Costa et al. 2008, Alencar et al. 2010, Santos et al. 2011), porém estudos de acompanhamento desses sistemas, dos fatores limitantes e da eficácia de estratégias de intervenção, até onde se sabe, não foram realizados. Diante do exposto, objetivou-se, mediante um estudo multidisciplinar, acompanhar propriedades produtoras de leite caprino no semiárido paraibano, identificar os principais fatores limitantes e propor e avaliar estratégias de intervenção.

\section{MATERIAL E MÉTODOS}

O estudo incluiu oito propriedades, cinco localizadas no Cariri e três, no Sertão Paraibano. As propriedades foram escolhidas com base em informações do médico veterinário da Cooperativa de Agroindústria Ltda (Cooagril) e dos agentes de desenvolvimento rural e social da Paraíba (ADRS), que identificaram propriedades que representavam os caprinocultores leiteiros da região. Para caracterização das propriedades, inicialmente, aplicou-se um questionário para obtenção de informações sobre área, rebanho, disponibilidade de forragens e manejo (nutricional, sanitário e reprodutivo), bem como dados de produção e principais enfermidades. Posteriormente, as propriedades foram visitadas, mensalmente, durante dois anos. Para a classificação do tamanho das propriedades, considerou-se o módulo fiscal dos municípios que corresponde a 55 hectares (INCRA 1980) e a determinação da lei $8629 / 1993$ que classifica as propriedades em pequena (área inferior a quatro módulos fiscais), média (entre 4 e 15 módulos) e grande (acima de 15 módulos) (Brasil 1993).

0 balanço forrageiro das propriedades foi obtido conforme considerações apresentadas quanto à disponibilidade de forragem na Caatinga na Paraíba (Bakke \& Pereira Filho 2010, Pereira Filho \& Bakke 2010), Pernambuco (Araújo Filho et al. 2002) e Ceará (Araújo Filho \& Crispim 2002). Para oferta de forragem na Caatinga, a estimativa foi feita a partir dos dados de Formiga et al. (2012) e para oferta de forragem em pastagem cultivada, adaptou-se a recomendação de Carvalho (2002). Quanto à estimativa da produção das espécies forrageiras cultivadas, foram consideradas as recomendações de Pires (2006) e Pereira Filho et al. (2011). 
Para aumentar a disponibilidade de forragens, sugeriu-se, após avaliação in loco das áreas, o plantio de capineiras de capim elefante (Pennisetum purpureum Schum.), sorgo (Sorghum bicolor L. Moench.), palma forrageira (Opuntia ficus-indica), gramíneas resistentes à seca como os capins buffel (Cenchrus ciliaris L.) e urocloa (Urochloa mosambicensis (Hack.) Dandy.), bem como a criação de bancos de proteínas com leguminosas como a leucena (Leucaena leucocephala Lam.). Foram fornecidas, também, informações sobre manejo adequado de áreas com forrageiras já estabelecidas e processos de conservação de forragens como a ensilagem e a fenação.

Os dados pluviométricos foram obtidos com a Agência Executiva de Gestão das Águas (AESA 2012) e a Empresa de Assistência Técnica e Extensão Rural do Estado da Paraíba (Emater-PB 2012). Todos os animais foram identificados para viabilizar a escrituração zootécnica e foram entregues planilhas aos produtores para registros de produção, manejo sanitário e produtivo, nascimentos, morte, venda e compra de animais. Através de pesagem mensal do leite produzido por cada cabra foi feito o controle de produção de leite. Para identificação das principais enfermidades, os animais foram, regularmente, examinados e, quando necessário, coletava-se material para exames laboratoriais. Para avaliação da ocorrência de mastite clínica e subclínica foi realizado exame físico da glândula mamária, testes da caneca de fundo escuro e, a cada dois meses, o Califórnia Mastite Test (CMT) e a bacteriologia. A avaliação do grau de infecção por parasitos gastrintestinais foi realizada, mensalmente, mediante contagem de ovos por grama de fezes de $10 \%$ do rebanho. Em rebanhos com número reduzido de animais, coletava-se, no mínimo, 10 amostras. No caso de suspeita de resistência aos anti-helmínticos, testes de resistência foram realizados de acordo com metodologia de Coles et al. (1992). Para avaliar, estatisticamente, se houve modificações no tamanho dos rebanhos durante o período do estudo utilizou-se análise de variância. A análise de regressão linear múltipla foi utilizada para identificação da influência da carga parasitária, precipitação pluviométrica, mastite clínica, mastite subclínica e linfadenite caseosa na produção de leite. Para verificar se houve diferenças entre a prevalência de mastite, mastite subclínica e linfadenite caseosa entre o primeiro e segundo ano foi realizada análise com os testes t para amostras dependentes.

\section{RESULTADOS E DISCUSSÃO}

\section{Caracterização}

Todas as propriedades foram classificadas como pequenas propriedades e as áreas variaram entre 10 e 100 hectares. Destas, seis tinham tamanho inferior a um módulo fiscal e apenas duas possuíam área entre um e dois módulos. 0 regime de criação nas oito propriedades era semi-intensivo.

Os produtores iniciaram a atividade motivados pelo Programa do Leite criado em 2003 na Paraíba. Anteriormente, estes desenvolviam atividades na pecuária de corte. Observou-se que, nos sistemas estudados, poderia ser utilizado o termo "pecuária familiar", que, de acordo com Porto \& Bezerra (2009), é recente e de uso restrito, utilizado para produtores que se dedicam, basicamente, à pecuária e áreas de agricultura de auto-consumo. Dos oito produtores, dois dependiam, exclusivamente, da produção de leite; desses, um recebia bolsa família e o outro tinha um membro da família que recebia aposentadoria. Três produtores tinham outro emprego fora da propriedade. Em uma propriedade, outros membros da família trabalhavam fora ou eram aposentados. Um produtor criava bovinos de leite e corte, além de um membro da família receber aposentadoria. Outro produtor tinha também bovinos na propriedade. Foi constatado que os produtores apresentavam sérias dificuldades econômicas para se manter na atividade, principalmente, durante a seca, quando dependem de políticas governamentais que assegurem bons preços do leite e do recebimento dos pagamentos, sem atrasos.

No início do estudo, o número médio de animais nas propriedades era 53 cabeças, ao final do primeiro ano passou a 62 e para 49, no último ano. Na análise estatística houve redução significativa no número total de cabeças $(\mathrm{P}<0,05)$. A redução ocorreu pela venda de animais devido ao longo período de estiagem no segundo ano, durante o qual a precipitação pluviométrica nos municípios do estudo variou entre 182 e $289,7 \mathrm{~mm}$, inferior à precipitação do ano anterior, cujos valores variaram entre 1033,3 e $1221,3 \mathrm{~mm}$. Em estudos anteriores, já havia sido relatada a venda de animais como estratégia para enfrentar a seca (Queiroz et al. 1986, Filho et al. 2000, Costa et al. 2008). A venda de animais, como matrizes e novilhas, acarreta perda de material genético e dificulta, após o período crítico, o retorno da atividade nos níveis anteriores. Filho et al. (2000) consideraram que a venda programada de animais seria uma estratégia correta para períodos de estiagem prolongada, desde que realizada, adequadamente. A redução do rebanho começaria pela venda de todos os machos, a ser efetivada antes do início do período mais seco, tão logo se confirmassem os níveis insuficientes de precipitação. Sequencialmente, seriam comercializadas as matrizes mais velhas, de baixa fertilidade, baixo desempenho, ou com defeitos e as crias em aleitamento. 0 importante, numa situação emergencial, não é tentar manter todo o rebanho, mas garantir a sobrevivência do maior número possível de matrizes jovens prontas para a reprodução, com a volta do período normal de chuvas. Com esse núcleo de matrizes, o produtor terá preservado uma condição mínima de capital que possibilite iniciar seu processo de recuperação.

Nenhuma das propriedades tinha rebanho com padrão racial definido. Em duas propriedades, predominava a raça Saanen. Nas demais, os animais eram mestiços das raças Alpina, Alpina Americana, Alpina Britânica, Toggenburg, Anglo Nubiana e Muciana. Entre os proprietários havia uma tendência em escolher raças de aptidão leiteira, o que justifica a presença de muitos animais da raça Saanen. Porém, a observação de que os animais desta raça não têm boa rusticidade e são predispostos a enfermidades como carcinoma de células escamosas e ceratoconjuntivite têm influenciado os produtores a introduzir animais de raças mais adaptadas ao semiárido e que sejam, também, boas produtoras de leite.

Algumas raças são muito sensíveis às condições climáticas e geográficas, além de menos adaptadas às condições diferentes daquela do seu habitat natural. A escolha da raça deve, portanto, ser bem estudada. Muitos estudos foram realizados no semiárido nordestino por institutos de pesquisa e universidades para identificar as raças mais indicadas para a região (Silva et al. 2010, Silva et al. 2011, Souza et al. 2011); no entanto, até o momento, não há uma recomenda- 
ção definida. Há discrepância entre a opinião dos produtores, pesquisadores e institutos de pesquisa. Ações recentes, apoiadas pelo Governo do Estado da Paraíba e Governo Federal, como a importação de embriões para distribuição dos animais aos pequenos produtores incluíram embriões da raça Saanen e Alpina Britânica. Entretanto, as cabras das raças Saanen, Toggenburg e Alpina Britânica necessitam um ambiente menos rústico para não ter a produção comprometida (Tibúrcio 2012).

Apesar de quase todos os rebanhos no Cariri Paraibano incluírem reprodutores de animais mestiços de raças especializadas em produção de leite, a produção média não ultrapassa um litro de leite/animal/dia, o que demonstra a dificuldade dos animais manterem seu potencial produtivo (Souza et al. 2011). Fatores relacionados ao ambiente e criação desses animais como clima, sanidade, nutrição e manejo são responsáveis por essa limitação (Guimarães et al. 2009).

Alimentação do rebanho. Capineiras com capim-elefante e áreas de capim-buffel foram identificadas em seis propriedades e consideradas importantes fontes de volumosos. Porém, observou-se que o manejo das capineiras era inadequado, pois os produtores não realizavam o corte no tempo certo, levando à perda de qualidade nutricional e digestibilidade do capim. 0 manejo adequado do capim elefante, durante o período chuvoso, inclui um corte, a cada 60 ou 70 dias (com altura máxima de 1,5m e elevada proporção de folha), o que permite dois cortes com teor de matéria seca em torno de $25 \%$ e proteína acima de $8 \%$. No manejo tradicional, o capim é cortado com mais de $2 \mathrm{~m}$ de altura, elevada proporção de caule e fibra e baixo teor de proteína (José M. Pereira Filho, comunicação pessoal).

O cultivo da palma havia sido realizado por seis dos oito produtores, porém, devido à infestação pela cochonilha (Diaspis echinocacti), houve marcada redução desta cultura nas propriedades. Atualmente, os produtores procuram refazer as áreas com variedades resistentes por reconhecer a importância desta cultura como alternativa de alimento, durante a época seca.

Ao ser analisado o balanço anual de forragem do primeiro ano, sete propriedades tiveram déficit forrageiro na seca, duas apresentaram déficit durante o período chuvoso. Todos os proprietários foram orientados para aumentar as áreas de forragens. Seis acataram as indicações e aumentaram as reservas com plantio de sorgo (6), capim-buffel (2), capim-elefante (1) e palma-forrageira (5). No entanto, problemas de cultivo inadequado (palma) e acesso de animais as áreas plantadas (sorgo) foram identificados em três propriedades. No segundo ano, após as intervenções, seis das oito propriedades apresentaram déficit durante a seca e duas, durante a chuva. Considerando o balanço forrageiro anual, no primeiro ano, havia déficit em quatro propriedades e, no segundo ano, somente em duas. Analisando o balanço forrageiro nos dois anos, foi identificado que, em seis propriedades, a quantidade de forragem produzida na chuva seria suficiente para corrigir o déficit na seca, caso esta fosse armazenada, o que ressalta a importância das estratégias de conservação de forragens. Observou-se que há interesse dos proprietários na ampliação de seus recursos forrageiros, setor no qual as intervenções são bem aceitas, porém os custos implicados e as dificuldades de acesso a implementos agrícolas e mão de obra para o preparo da terra são considerados fatores limitantes. Além disso, a assistência técnica nesta área é insuficiente e muitos problemas são observados na implantação e manutenção das culturas, desestimulando a continuidade das inovações.

Em relação às práticas de armazenamento de forragens, sete proprietários conheciam sua importância e já as haviam aplicado, porém encontraram limitações financeiras, dificuldades na confecção dos silos e na confecção e armazenagem do feno, principalmente, quando este era feito com capim elefante. Além disso, muitos produtores têm a interpretação equivocada de que o feno é forragem seca de baixo valor nutricional; desta forma preferem manter culturas permanentes com irrigação nos tempos críticos. Durante o período do estudo, os proprietários foram orientados a utilizar técnicas de armazenamento de forragens, porém apenas quatro armazenaram em silos, mas problemas como baixa aceitabilidade por parte dos animais e infiltração de água foram observados. A maior aceitabilidade da ensilagem como forma de armazenagem de forragem difere dos dados de Silva et al. (2004) que citam a fenação como sendo mais utilizada que a ensilagem, talvez pela aparente simplicidade do processo. A aquisição de máquinas de uso comum pelas associações de produtores, cooperativas, ou órgãos governamentais e uma assistência técnica especializada na produção e conservação de forragem no semiárido podem ser mecanismos para solucionar a deficiência forrageira durante a seca.

Como forma de amenizar a escassez de volumoso e aumentar a produção, os proprietários utilizavam ração concentrada, em grandes quantidades, o que encarece muito a produção, ou em quantidades muito baixas, em épocas de atraso de pagamentos e dificuldades financeiras, não atendendo às necessidades dos animais. Todos os produtores administravam concentrado às cabras em lactação, mas nenhum administrava maior quantidade as cabras mais produtivas. Somente um proprietário fornecia concentrado às cabritas e dois forneciam às novilhas, quando estavam próximas do parto.

A forma de fornecimento de concentrado foi semelhante à registrada por Costa et al. (2010) em estudo realizado na Paraíba no qual identificou a suplementação com produtos fornecidos prontos, ou na forma de misturas de farelos, sem maiores preocupações com o atendimento das exigências nutricionais por categoria. A oferta de concentrado era, normalmente, aplicada aos animais que estavam em fase de lactação, ou em períodos de estiagem, numa tentativa de salvar os rebanhos da morte por desnutrição.

\section{Produção de leite}

A média da produção de leite nas propriedades estudadas foi de 1,19 litros por cabra, variando entre 0,8 e 1,7 litros, valores próximos aos relatados por Bandeira et al. (2007) em estudo com cabras leiteiras no Cariri Paraibano que identificaram uma produção média inferior a 1 litro de leite/animal/dia. 
No período do estudo, observou-se que as variações na produção de leite não seguiam um padrão definido ou associado à estação do ano. Quatro propriedades mantiveram bons níveis de produção, considerando os valores regionais, independente da estação do ano. Em três destas quatro propriedades havia boa disponibilidade de forragens e, em uma delas, os animais eram, adequadamente, suplementados com concentrado. Em uma propriedade, verificou-se que o nível de produção ficou abaixo da média geral durante todo o período do estudo, havia déficit de forragem (inclusive no período chuvoso) e a suplementação com concentrado era inadequada. Os dados obtidos e as observações feitas demonstram que, de acordo com o descrito por Pimenta Filho et al. (2009), há baixa correlação entre as variáveis pluviométricas com a produção de leite, sendo o manejo alimentar mais determinante e, se este for feito de forma adequada, pode contribuir para redução da sazonalidade da produção.

Um dos fatores identificados para essa variação da produção foi a irregularidade dos pagamentos do leite, que limitava o investimento em novas tecnologias e até mesmo a aquisição de alimento para os animais. Esta situação levava os produtores a buscarem outras formas de renda para a família e estes se ausentavam da propriedade, durante a maior parte do dia, ou desistiam da atividade.

\section{Instalações}

Em relação às instalações, foi observado que o curral de chão batido com pequena área coberta com telhas predominava nas propriedades. A estabulação livre é considerada vantajosa, pois envolve menos custos, promove conforto, necessita de pouca mão de obra e permite que os animais se exercitem. Identificou-se que as áreas dos currais, de forma geral, atendiam as necessidades dos animais, porém a área coberta com telhas era pequena e tinha beirais também muito pequenos. 0 recomendado é que os animais adultos disponham de uma área coberta de $1,0 \mathrm{~m}^{2} /$ animal e que os beirais tenham $1,5 \mathrm{~m}$, em regiões com chuvas de vento abundantes (Borges e Gonçalves 2007). Apesar deste tipo de chuva não ser uma característica da região semiárida, beirais pequenos permitem a incidência de raios solares no caso de posicionamento incorreto do telhado, causando desconforto térmico, nas horas mais quentes.

Os problemas mais graves de instalações foram identificados nos cabriteiros que eram pequenos em 6 das 8 propriedades. 0 cabrito deve ter uma área disponível de 0,4 $\mathrm{m}^{2}$ por cabeça (Patil 2010). Outro problema frequente era a contaminação dos alimentos e água com fezes, devido ao inadequado posicionamento de comedouros e bebedouros, os quais não eram colocados no lado externo, favorecendo a ocorrência de infecções neonatais e coccidiose. Além disso, não havia proteção contra chuva, ventos e radiação solar e cabritos de várias idades eram mantidos juntos. Ovinos e caprinos necessitam de instalações simples; no entanto, com condições mínimas, especialmente, a proteção contra intempéries e predação (Patil 2010).

Outro problema identificado nas instalações foi a ausência de uma área reservada para maternidade, em todas as propriedades. Observou-se que os partos ocorrem a campo, ou dentro do curral, o que permite a contaminação do neonato com patógenos ambientais e dificulta o manejo adequado, a desinfecção do umbigo e a supervisão da ingestão de colostro do neonato. Estas condições podem predispor às infecções neonatais, já consideradas por Medeiros et al. (2005) e Nóbrega Júnior et al. (2005), como importante causa de mortalidade de cabritos e cordeiros. 0 capril maternidade deve incluir uma área de $2,0 \mathrm{~m}^{2}$ por cabra e deve acomodar de 5 a 6 cabras (Borges \& Gonçalves 2007). A falta de um local para isolamento dos animais doentes, identificada em sete propriedades, é outro aspecto preocupante do ponto de vista sanitário, principalmente, ao se considerar que, nos rebanhos da região, há alta prevalência de animais com linfadenite caseosa. Recomenda-se que estes espaços sejam individuais e que tenham dimensão de $3 \times 2 \mathrm{~m}$.

\section{Escrituração zootécnica}

Três proprietários faziam algum tipo de anotação em uma caderneta, como quantidade de leite deixado na usina e alguns gastos com o rebanho. Anotações dos nascimentos e óbitos eram realizadas apenas em uma propriedade. Durante o período do estudo, tentou-se melhorar a escrituração zootécnica. Os animais foram identificados e disponibilizaram-se quadros brancos nos currais, pincéis e planilhas, mas apenas um proprietário efetuou o registro de dados corretamente. Porém todos fizeram algum tipo de anotação, especialmente, em relação ao nascimento de cabritos, peso ao nascimento, óbitos e vendas de animais. O desinteresse no registro dos dados, geralmente, é atribuído, pelos extensionistas, ao desinteresse do produtor, porém, é consequência da dificuldade deste identificar a importância do registro como ferramenta no manejo geral do rebanho. Em cartilhas confeccionadas para produtores, é solicitado o preenchimento de fichas que contêm informações sobre raça, pelagem, idade, número do animal, peso ao nascer e aos 30, 60, 90, 180 e 360 dias de idade, data da cobertura, nome do reprodutor, data e tipo de parto, sexo da cria, registro de óbitos, data e tipo de ocorrências com o rebanho, controle de entrada e saída de animais, controle leiteiro, cadastro e genealogia (SEBRAE 2000). Considerando que, inicialmente, o preenchimento dessas fichas pode ser trabalhoso para os produtores, sugere-se para os sistemas produtivos de leite caprino estudados, que a escrituração zootécnica seja ensinada e implantada, gradativamente. Inicialmente, os animais deveriam ser identificados e solicitado o registro dos dados considerados mais importantes. Posteriormente, deveria ser feito o processamento e análise, demonstrando-se ao proprietário os resultados positivos dos registros para incentivar o processo.

\section{Manejo de ordenha}

Nenhum dos produtores realizava um manejo de ordenha adequado, porém algumas medidas preconizadas eram realizadas, tais como: lavagem dos tetos ( 6 de 8 propriedades), secagem dos mesmos (6/8) e pós-dipping (5/8). Das seis propriedades que lavavam os tetos, em três a lavagem era feita apenas com água, em uma com água e sabão e, em 
duas, era utilizada água clorada. Procedimentos inadequados eram realizados, também, na secagem, pois quatro dos seis proprietários que lavavam os tetos, os enxugavam com pano. Apesar de terem sido identificadas falhas no manejo de ordenha, a prevalência de mastite subclínica, no início do estudo, em todas as propriedades variou de 6,4 a $27,2 \%$, com média de $15,1 \%$. Os limites aceitáveis estão entre $7 \%$ e 34\% (Contreras et al. 2003).

Em relação ao manejo de ordenha, recomendou-se lavar os tetos com água clorada a $1 \%$, enxugar com papel toalha e, após ordenha, utilizar pós-dipping com iodo ou água clorada. A modificação mais expressiva adotada em todas as propriedades foi a substituição da toalha de pano pelo papel toalha descartável. No segundo ano, a prevalência de mastite subclínica variou de 5,2\% a 18,4\% (com média de $8,6 \%$ ). Na análise estatística da prevalência de mastite subclínica, a diminuição de $15,1 \%$ para $8,6 \%$ entre o primeiro e segundo ano, depois das intervenções, o valor de $\mathrm{p}$ foi 0,079, bem próximo do limite de 0,05 .

\section{Manejo reprodutivo}

Todos os proprietários separavam o reprodutor e realizavam a cobertura das fêmeas de acordo com critérios estabelecidos por eles mesmos, geralmente, mediante a observação de cio e/ou quando as fêmeas estavam diminuindo o leite; entretanto, não havia um período de lactação bem definido, variando entre sete e 14 meses, porém com média de 10 meses. A duração da lactação foi um dado difícil de ser estabelecido, uma vez que os proprietários não anotavam a data de parição, tornando a informação bastante subjetiva. Durante as visitas, encorajou-se a utilização do intervalo entre partos de 12 meses, com 10 meses de lactação, o que está sendo acolhido em todas as propriedades. Durante a estação de monta observou-se que os produtores preferiam colocar todos os animais para serem cobertos de uma única vez, entretanto, estimulados pelas usinas a não deixar de fornecer leite no período seco das cabras, havia uma divisão do rebanho para a produção de leite por todo o ano.

O manejo reprodutivo é pouco estudado na região semiárida e não está, ainda, estabelecido qual o mais adequado, uma vez que diversos fatores devem ser considerados para o estabelecimento deste manejo, entre eles disponibilidade de forragens, período de maior mortalidade de crias e ocorrência de transtornos metabólicos. Costa et al. (2008) observaram, em estudo sobre a caracterização do sistema de produção caprino e ovino na região semiárida do Estado da Paraíba, que não há métodos de seleção e de manejo reprodutivo visando a melhoria da produção, ou mesmo para padronização do rebanho.

\section{Práticas sanitárias e principais enfermidades diagnos- ticadas}

Dentre as práticas sanitárias, quatro proprietários vacinavam somente para clostridiose, com vacinas polivalentes; três vacinavam para raiva e clostridiose e um não vacinava o rebanho. Durante todo o período, não foi diagnosticado nenhum surto de doenças causadas por Clostridium spp. e foi diagnosticado um surto de raiva em uma propriedade que não vacinava o rebanho contra a doença. A repetição da utilização de vermífugos, uma semana após dosificação foi uma falha identificada, além disso, as vermifugações eram feitas sem planejamento e, geralmente, os anti-helmínticos eram administrados em subdoses, já que os produtores desconheciam as doses adequadas para caprinos (50 a 100\% maiores do que para ovinos) da maioria dos anti-helmínticos, pois essa informação não está descrita nas bulas dos medicamentos (Costa et al. 2011). Após a adoção do exame periódico de número de ovos nas fezes e subsequente tratamento, quando a infestação ultrapassava 500-1000 ovos não foram registrados focos de helmintose gastrintestinal. Outra técnica adotada foi a realização de testes de resistência após a observação de tratamentos ineficientes. Em sete propriedades, foram encontrados diversos graus de resistência aos diferentes princípios ativos utilizados (lactonas macrocíclicas, salicilanilidas, benzimidazóis, fosforados (triclorfom) e imidotiazóis), sendo adotadas medidas adequadas para a utilização racional dos anti-helmínticos. A adoção dessas medidas foi eficiente não só para diminuir o número de focos de parasitose, mas também para diminuir e controlar a resistência parasitária. Outras enfermidades diagnosticadas em animais de diferentes idades foram linfadenite caseosa (em todas as propriedades), ectima contagioso (em quatro) e ceratoconjuntivite (em três). Casos esporádicos de pododermatite, carcinoma de células escamosas, acidose e abscessos medulares foram, também, constatados. No primeiro ano do estudo, a prevalência de linfadenite variou de $3,2 \%$ a $26 \%$ (com média de 13,3\%, em todas as propriedades). Como medida de controle, recomendou-se abertura do abscesso, incineração do material drenado, aplicação de iodo a $10 \%$ no local por três dias consecutivos e isolamento do animal, até cicatrização da pele. Houve diminuição da prevalência em todas as propriedades que, no segundo ano, variou de zero a $24 \%$ (com média de $7,8 \%$ ). Na análise estatística, o valor do $\mathrm{P}$ ficou bem próximo ao limite de significância $(\mathrm{P}=0,065)$, demonstrando que as medidas de controle instituídas foram adequadas.

No primeiro ano deste estudo, em duas propriedades, a mortalidade de animais foi $11 \%$ e $68 \%$, maior do que as aceitáveis (8\%) (Ribeiro 1997). Nas demais propriedades, a taxa de mortalidade variou de 0 a $6,45 \%$. No segundo ano, duas propriedades apresentaram taxas de 20 e $24 \%$. As principais causas de mortalidade foram eimeriose e predação. Malformações em animais jovens foram identificadas em uma propriedade. Abortos, repetição de cio, retenção de placenta ou natimortalidade foram relatados por $75 \%$ dos proprietários. As taxas de aborto variaram de 2,3 a 5,6\%, mas uma propriedade apresentou, durante a seca de 2012, 26\% de abortos associados com a ingestão de Aspidosperma pyicollum. A frequência de repetição de cio variou de 2,5 a 33,8\%. A implantação da escrituração zootécnica, inclusive controle reprodutivo e dados de produção, contribuiu, significativamente, para a constatação da situação do desempenho real dos rebanhos das fazendas e sua continuação, no futuro, permitirá tomar decisões adequadas para diminuir os problemas reprodutivos encontrados. 


\section{CONCLUSÕES}

A caprinocultura leiteira do semiárido paraibano caracteriza-se por mão de obra familiar, com baixa renda dos produtores, baixa produção de leite dos rebanhos. A maioria dos produtores depende de outras fontes de renda, incluindo aposentadoria, bolsa família ou empregos fora da propriedade.

Apesar da aparente simplicidade dos sistemas produtivos de leite caprino da região semiárida, observa-se que problemas das mais diversas ordens estão presentes e que se agravam ao se considerar a pequena capacidade de investimento na atividade e as dificuldades para enfrentar a seca.

A assistência técnica permanente permitiu que problemas identificados, principalmente, em relação ao manejo sanitário e alimentar fossem minimizados, mas esta precisa ser, essencialmente, multidisciplinar para que resultados mais significativos sejam visualizados.

0 estudo demonstrou que os produtores aceitam a implantação de novas tecnologias, desde que estas sejam gradativamente implantadas e adequadas aos sistemas.

Além de uma assistência técnica adequada, os produtores de leite de cabra no Cariri e Sertão Paraibano dependem de políticas governamentais que assegurem bons preços para o leite e de políticas adequadas para a convivência com a seca.

Agradecimentos.- Este trabalho foi financiado pelo CNPq (Proc.558932/ 2010-0).

\section{REFERÊNCIAS}

AESA 2012. Agência Executiva de Gestão das Águas. <http://www.aesa. pb.gov.br/> Acesso em 20 jul. 2012.

Alencar S.P., Mota R.A., Coelho M.C.O., Nascimento S.A., Abreu S.R.D.O. \& Castro R.S. 2010. Perfil sanitário dos rebanhos caprinos e ovinos no sertão de Pernambuco. Ciênc. Anim. Bras. 11(1):131-140.

Araújo Filho J.A. \& Crispim S.M.A. 2002. Pastoreio combinado de bovinos, caprinos e ovinos em áreas de caatinga no Nordeste do Brasil. Conferência Virtual Global sobre Produção Orgânica de Bovinos de Corte. University of Contestado (UnC), Concordia/SC, Brasil. Embrapa Pantanal, Corumbá/MS, Brasil, p.1-7.

Araújo Filho J.A., Carvalho F.C., Garcia R. \& Sousa R.A. 2002. Efeitos da manipulação da vegetação lenhosa sobre a produção e compartimentalização da fitomassa pastável de uma caatinga successional. Revta. Bras. Zootec. 31:11-19.

Bakke O.A. \& Pereira Filho J.M. 2010. Produção e utilização da forragem de espécies lenhosas da caatinga, p.160-179. In: Gariglio M.A., Sampaio E.V.S.B., Cestaro L.A. \& Kageyama P.Y. (Eds), Uso Sustentável e Conservação dos Recursos Florestais da Caatinga. Serviço Florestal Brasileiro, Brasília.

Bandeira D.A., Castro R.S., Azevedo E.O., Melo L.S.S. \& Melo C.B. 2007. Características da produção da caprinocultura leiteira na região do cariri na Paraíba. Ciênc. Vet. Tróp., Recife, 10(1):29-35.

Borges I. \& Gonçalves L.C. 2007. Manual Prático de Caprino e Ovinocultura da Universidade Federal de Minas Gerais, Belo Horizonte. 191p.

Brasil 1993. Lei no 8629/1993. Estabelece o tamanho das propriedades rurais. Reforma do Códico Florestal. Disponível em <http://www12. senado.gov.br/codigoflorestal/infograficos/pequena-propriedade-e-agricultura-familiar> Acesso em 22 ago. 2012.

Carvalho P.C.F. 2002 Pastagem cultivada para caprinos e ovinos. Anais do Seminário Nordestino de Pecuária, Fortaleza/CE, p.22-43.

Coles G.C., Bauer C. \& Borgsteede F.H.M. 1992. World Association for the
Advancement of Veterinary Parasitology (WAAVP): methods for detection of anthelmintic resistance in nematodes of veterinary importance. Vet. Parasitol. 44:35-44.

Contreras A., Luengo C., Sanchez A. \& Corrales J.C. 2003. The role of intramammary pathogens in dairy goats. Livest. Prod. Sci. 79:273-283.

Costa R.G., Almeida C.C., Pimenta Filho E.C., Holanda J.E.V. \& Santos N.M. 2008. Caracterização do sistema de produção caprino e ovino na região semi-árida do estado da Paraíba, Brasil. Arch. Zootec. 57 (218):195-205.

Costa A.R., Lacerda C. \& Freitas F.R.D. 2010. A criação de ovinos e caprinos em Campos Sales. Cad. Cultura e Ciência 2(2):55-63.

Costa V.M.M., Simões S.V.D. \& Riet-Correa F. 2011. Controle das parasitoses gastrointestinais em ovinos e caprinos na região semi-árida do Nordeste do Brasil. Pesq. Vet. Bras. 31(1):65-71.

Emater-PB 2012. Arquivos internos sobre a pluviometria na região nos anos de 2010, 2011 e 2012. Empresa de Assistência Técnica e Extensão Rural do Estado da Paraíba, João Pessoa.

Formiga L.D.A.S., Pereira Filho J.M. \& Oliveira N.S. 2012. Oferta de forragem em Caatinga raleada e enriquecida com capim buffel (Cenchrus ciliaris L.), submetida ao pastejo de caprinos e ovinos. Acta Scientiarum, Anim. Sci. 34(2):189-195.

Filho C.G., Soares J.G.G., Correia R.C. \& Araújo G.G.L. 2000. Subsídios para uma estratégia emergencial de redução dos efeitos da seca na pecuária do semi-árido brasileiro. Anais Congresso Mundial de Sociologia Rural e Congresso Brasileiro de Economia e Sociologia Rural. Embrapa Semi-Árido. Disponível em <http://www.alice.cnptia.embrapa.br/bitstream/doc/573960/1/OPB2510.pdf>

Guimarães V.P., Facó O., Bomfim M.A.D. \& Oliveira E.L.D. 2009. Sistema de produção de leite de cabra no semi-árido nordestino. IV Simpósio Internacional sobre Caprinos e Ovinos de Corte, João Pessoa, PB. <http:// www.alice.cnptia.embrapa.br/bitstream/doc/576099/1/AACSistemadeproducaodeleitedecabranoeemiaridonordestino.pdf> Acesso em 10 ago. 2012.

INCRA 1980. Instituto Nacional de Colonização e Reforma Agrária. Instrução especial no 20/80.28/05/1980. <http://www.incra.gov.br/index. php/institucionall/legislacao--/atos-internos/instrucoes/file/129-instrucao-especial-n-20-28051980> Acesso em 22 ago. 2012.

Lima G.F.C. 2009. Reservas estratégicas de forragem de boa qualidade para bovinos leiteiros, p.11-35. In: Brito A.S., Nobre F.V. \& Fonseca J.R.R. (Eds), Bovinocultura Leiteira: informações técnicas e de gestão. SEBRAE/RN, Natal. 320p.

Medeiros J.M., Tabosa I.M., Simões S.V.D., Júnior J.E.N. Vasconcelos J.S. \& Riet-Correa F. 2005. Mortalidades perinatal em cabritos no semi-árido da Paraíba. Pesq. Vet. Bras. 25(4):201-206.

Patil V. 2010. Housing systems, layout and design of different buildings for sheep and goat farms. Disponível em <https://sites.google.com/site/ viveklpm/sheep-and-goat-production-management/housing-systems-layout-and-design-of-different-buildings-for-sheep-and-goat-farms. 2010> Acesso em 17 ago. 2012

Pereira Filho J.M. \& Bakke O.A. 2010. Produção de forragem de espécies herbáceas da caatinga, p.145-159. In: Gariglio M.A., Sampaio E.V.S.B., Cestaro L.A. \& Kageyama P.Y. (Eds), Uso Sustentável e Conservação dos Recursos Florestais da Caatinga. $2^{\mathrm{a}}$ ed. Serviço Florestal Brasileiro, Brasília.

Pereira Filho J.M., Silva A.M.A. \& Cézar M.F. 2011. Manejo da caatinga para produção de caprinos e ovinos. Anais XXI Congresso Brasileiro de Zootecnia, Maceió. Alagoas. (CD-ROM)

Pimenta Filho E.C., Morais S.A.N, Costa R.G., Almeida C.C.A. \& Medeiros G.R. 2009. Correlação entre pluviosidade e características produtivas no semi-árido paraibano. Revta Bras. Zootec. 38(9):1785-1789.

Pires W. 2006. Manual de Pastagem: formação, manejo e recuperação. Aprenda Fácil, Viçosa. 302p.

Porto R.G. \& Bezerra A.J.A. 2009. A pecuária familiar: categoria social no município de Bagé, RS: região da campanha meridional. Revta. Bras. Agrociência, Pelotas, 15:101-107.

Queiroz J.S., Gutierrez-Aleman N. \& León F.A.P. 1986. The ecology and management of small ruminant production systems in the Sertão of Ceará, in the Northeast of Brazil. Agr. Syst. 22:259-287. 
Ribeiro S.D.D.A. 1997. Caprinocultura: criação racional de caprinos. Editora Nobel, São Paulo. 318p.

SEBRAE 2000. Cartilha do Caprinocultor. Sebrae, João Pessoa. 22p.

Santos T.C.P.D., Alfaro C.E.P. \& Figueiredo S.M.D. 2011. Aspectos sanitários em criações de caprinos e ovinos na microrregião de Patos, região semi-árida da Paraíba. Ciênc. Anim. Bras. 12(2):206-212.

Silva M.M.C., Guim A., Pimenta Filho E.C., Dornellas G.V., Sousa M.F. \& Figueiredo M.V. 2004. Avaliação do padrão de fermentação de silagens elaboradas com espécies forrageiras do estrato herbáceo da Caatinga nordestina. Revta Bras. Zootec. 33:87-96.

Silva E.M.N., Souza B.B., Sousa O.B., Silva G.A. \& Freitas M.M.S. 2010. Avaliação da adaptabilidade de caprinos ao semiárido através de parâmetros fisiológicos e estruturas do tegumento. Revta Caatinga, Mossoró, 23(2):142-148.
Silva G.A., Lopes J.J. \& Marques B.A.A. 2011. Efeito do ambiente sobre os parâmetros fisiológicos de cabras Parda Alpina e Anglo Nubiana criadas em sistema semi-intensivo no semiárido paraibano. IV Congresso Brasileiro de Biometeorologia, Piracicaba, São Paulo. (CD-ROM).

Souza B.B., Silva E.M.N., Silva G.A. \& Nogueira F.R.B. 2011. Leite de cabra: raças utilizadas e sistemas de alimentação utilizadas no Cariri Paraibano. Disponível em <http://www.cstr.ufcg.edu.br/bioclimatologia/resumos/leite_cabra_racas_utilizadas sistemas_alimentacao.pdf>

Suassuna J. 2012. Leite de Cabra na Paraíba. Revta Berro 155. <http:// www.revistaberro.com.br/?materias/ler,1887> Acesso em 6 ago. 2012.

Tibúrcio P. 2012. Características das principais raças de cabras leiteiras no Brasil. Disponível em <http://www.tecnologiaetreinamento.com. br/ovinos-e-caprinos/caracteristicas-das-principais-racas-de-cabras-leiteiras-criadas-no-brasil/> Acesso em 19 ago. 2012. 